EXTENDED REPORT

\title{
Susceptibility to ankylosing spondylitis: no evidence for the involvement of transforming growth factor $\beta 1$ (TGFB 1) gene polymorphisms
}

\author{
M van der Paardt, J B A Crusius, M A García-González, B A C Dijkmans, A S Peña, I E van der \\ Horst-Bruinsma
}

Ann Rheum Dis 2005;64:616-619. doi: 10.1136/ard.2004.027698

\begin{abstract}
See end of article for authors' affiliations

.....................

Correspondence to: Dr I E van der HorstBruinsma, VU University Medical Centre, Department of Rheumatology, Room 4A42, PO Box 7057, 1007 MB Amsterdam, Netherlands: secr.reumatologie@ vumc.nl
\end{abstract}

Accepted 22 August 2004
Background: Genetic factors are thought to be crucial in the pathogenesis of ankylosing spondylitis. Transforming growth factor $\beta 1$ (TGF $\beta 1$ ) is a multifunctional cytokine that plays a key role in inflammation. Two functional single nucleotide polymorphisms (SNPs) in the TGFB1 gene have been described: TGFB1 T869C and TGFB 1 G915C.

Objective: To determine whether these SNPs contribute to ankylosing spondylitis susceptibility or its disease characteristics.

Methods: Genomic DNA was isolated from the peripheral blood of 134 patients with ankylosing spondylitis and 194 healthy blood donors. All subjects were unrelated and of white Dutch ethnicity. The diagnosis of ankylosing spondylitis was made according to the modified New York criteria. The TGFB1 T869C and TGFB1 G915C SNPs were genotyped by a polymerase chain reaction-single strand conformation polymorphism haplotyping method.

Results: No significant differences were found between patients and controls in genotype, allele, and haplotype frequencies or in the carrier rate of the rare alleles of the TGFB1 T869C and TGFB1 G915C SNPs.

Conclusions: TGFB1 T869C and TGFB1 G915C SNPs are not major factors in the susceptibility to ankylosing spondylitis or its disease characteristics.
A nkylosing spondylitis (AS) is a common familial rheumatic disorder. The disease is characterised by chronic inflammation of the sacroiliac joints and the vertebral column. The inflammatory process leads gradually to fibrosis and calcification of the spine and sacroiliac joints. Ultimately, ossification, interosseous bridging, and ankylosis can occur. Spinal osteoporosis is often observed in patients with active disease and is probably induced by regulatory cytokines. ${ }^{12}$

The precise aetiology of the disorder remains unclear, though heritability plays a major role. Twin studies suggest that up to $97 \%$ of the susceptibility to AS can be attributed to genetic factors. ${ }^{3}$ For over 30 years the main known genetic component has been human leucocyte antigen (HLA) B27. More than $95 \%$ of white patients with primary AS and at least $50 \%$ of those with AS associated with psoriasis or inflammatory bowel disease are HLA-B27 positive, whereas HLA-B27 is present in only $8 \%$ of the general Dutch population. ${ }^{4}$

However, family studies have shown that the major histocompatibility complex (MHC), including HLA-B27, contributes less than $40 \%$ to the recurrence risk ratio in AS. ${ }^{5}$ Apart from the MHC, Laval et al identified six other loci-on chromosomes 1p, 2q, 9q, 10q, 16q, and 19q-that are linked to AS. The peak of linkage on chromosome 19 was observed with the marker D19S420 (LOD score 3.58). ${ }^{5}$

The TGFBI gene encoding the human transforming growth factor $\beta 1$ (TGF $\beta 1$ ) is located 1.8 Mb from marker D19S420 on chromosome $19 \mathrm{q} 13 .{ }^{6}$ TGF $\beta 1$ is a multifunctional cytokine involved in the regulation and proliferation of cells. This cytokine promotes differentiation of leucocytes, but has inhibitory effects on proliferation of $\mathrm{T}$ lymphocytes and activation of macrophages, suggesting a regulatory role in inflammatory states. ${ }^{7}$ TGF $\beta 1$ is known to be able to control the production of many components of the extracellular matrix and to be a potent regulator of osteoblast proliferation and differentiation. ${ }^{8}$ In general, TGF $\beta$ stimulates cartilage and bone formation, but the precise effects are complex, depending on the concentration of TGF $\beta$, whether the bone is growing or damaged, the state of activation of the cells, and the presence of other factors, including hormones. ${ }^{9}$ Moreover, TGF $\beta$ is required to switch B cells into production of IgA, ${ }^{10}{ }^{11}$ which is often increased in AS patients. ${ }^{12}$ Therefore, TGF $\beta$ is a good candidate for a key cytokine in an inflammatory disease such as AS, in which new bone formation and ultimately ankylosis of the sacroiliac joints and the vertebral column are major symptoms and fibrosis is a related phenomenon. ${ }^{13-15}$

Recently, the single nucleotide polymorphisms (SNPs) at positions $+869(\mathrm{~T} \rightarrow \mathrm{C})$ and $+915(\mathrm{G} \rightarrow \mathrm{C})$ in the signal protein sequence of the TGFBI gene, which change codon 10 (Leu10Pro) and codon 25 (Arg25Pro), respectively, ${ }^{16}$ have been reported to be related to variations in the production of TGF $\beta 1$, both in vitro ${ }^{17}$ and at the serum level. ${ }^{18}$

In the present study we investigated whether the TGFBI T869C and TGFB1 G915C SNPs or their haplotypes are associated with susceptibility to or disease characteristics of AS.

\section{METHODS}

Subjects

After informed consent, 134 AS patients were recruited from the outpatient department of rheumatology of the Jan van

Abbreviations: HLA, human leucocyte antigen; HWE, HardyWeinberg equilibrium; MHC, major histocompatibility complex; SNP, single nucleotide polymorphism; TGF $\beta 1$, transforming growth factor $\beta 1$ 
Table 1 Demographic and clinical characteristics of patients with ankylosing spondylitis $(n=134)$

\begin{tabular}{ll}
\hline Characteristic & Frequency \\
\hline Age (years)* & $50.9(12.9)$ (19 to 79) \\
Age at first complaints (years)† & $23.0(19.0$ to 31.5) \\
Age at diagnosis (years) & $34.7(10.6)(16$ to 63) \\
Years between first complaints and diagnosis† & $7.0(2.0$ to 12.5) \\
Women & $18.7 \%$ \\
HLA-B27 positive & $94 \%$ \\
Iridocyclitis & $43 \%$ \\
Peripheral arthritis & $41 \%$ \\
First degree relatives with AS & $28 \%$ \\
\hline & \\
*Mean (SD) (range). & \\
†Median (interquartile range). & \\
AS, ankylosing spondylitis. &
\end{tabular}

Breemen Institute. They all fulfilled the diagnostic requirements of AS according to the modified New York criteria. ${ }^{19}$ Controls were 194 randomly selected healthy blood donors from the Amsterdam region. All subjects were unrelated and of white Dutch ethnicity.

\section{PCR-SSCP analysis}

A polymerase chain reaction-single strand conformation polymorphism (PCR-SSCP) method was optimised for the simultaneous detection of the SNPs at positions +869 and +915 in the TGFBI gene and their haplotypes. The method has been described previously by García-González et al. ${ }^{20}$ In that study in a Dutch population, the alleles were shown to form three haplotypes, denoted as haplotype 1 (TGFBI+ $869 \mathrm{~T}-T G F B 1+915 \mathrm{G})$, haplotype 2 (TGFBI+869C-TGFBI+ 915G), and haplotype 3 (TGFBI+869C-TGFBI+915C). In brief, the region containing the SNP at position +869 (NCBI SNP CLUSTER ID: rs1982073) and the SNP at position +915 of the TGFB1 gene (NCBI SNP CLUSTER ID: rs 1800471) was amplified by PCR in a Perkin-Elmer 9600 thermal cycler (Perkin-Elmer, Norwalk, Connecticut, USA) according to the following parameters: $97^{\circ} \mathrm{C}$ for 90 seconds, $61^{\circ} \mathrm{C}$ for 90 seconds, and $72^{\circ} \mathrm{C}$ for 60 seconds for three cycles, followed by 32 cycles of $97^{\circ} \mathrm{C}$ for 30 seconds, $61^{\circ} \mathrm{C}$ for 60 seconds, and $72^{\circ} \mathrm{C}$ for 60 seconds, with a final elongation at $72^{\circ} \mathrm{C}$ for 10 minutes.

PCR products diluted twofold in $99 \%$ formamide were heated at $95^{\circ} \mathrm{C}$ for three minutes and placed on ice. Electrophoresis on a pre-cast non-denaturing $20 \%$ polyacrylamide PhastGel at $20^{\circ} \mathrm{C}$ and silver staining were done semiautomatically on the PhastSystem ${ }^{\mathrm{TM}}$ (Amersham Pharmacia, LKB Biotechnology AB, Uppsala, Sweden).

\section{Statistical analysis}

Allele and genotype frequencies were tested for HardyWeinberg equilibrium (HWE) by the $\chi^{2}$ test. To compare frequencies $\chi^{2}$ testing was used or, when appropriate, Fisher's exact test. A two sided $p$ value of $<0.05$ was considered significant. The magnitude of association was expressed as the odds ratio (OR) with $95 \%$ confidence intervals (CI). The statistical analyses were undertaken using SPSS 10.0 for Windows.

\section{RESULTS}

Characteristics of the 134 AS patients are summarised in table 1. Genotype and distribution of allele frequencies in AS patients and controls for the TGFBI T869C and TGFB1 G915C polymorphism are shown in table 2 .

The data for the controls were published previously by Schrijver et al. ${ }^{21}$ The genotype frequencies in the control group did not deviate from HWE equilibrium. No significant differences were observed between AS patients and controls in the frequencies of the carriership of the allele TGFBI 869C $(\mathrm{OR}=0.96(95 \% \mathrm{CI}, 0.69$ to 1.33$), \mathrm{p}=0.81)$ and the allele TGFB1 915C $(\mathrm{OR}=1.62(0.93$ to 2.84$), \mathrm{p}=0.09)$ (table 2$)$; neither were significant differences observed between AS patients and controls in the frequencies of the carriership of the three TGFB1 haplotypes (table 3).

No significant associations were found between carriage of either of the alleles TGFB1 869C and TGFB1 915C, or their haplotypes, and sex, past or present peripheral arthritis or acute anterior uveitis, age at first complaints, years between these first complaints and the diagnosis of AS, and the number of patients with at least one first degree family member with AS (data not shown).

\section{DISCUSSION}

In this study the TGFBI T869C and TGFBI G915C SNPs or their haplotypes were not significantly associated with susceptibility to AS or its manifestations in a white Dutch population. Genotype and allele frequencies of the TGFBI T869C and TGFBI G915C SNPs in our control population were similar to those reported in some European studies undertaken in healthy controls from Northern Ireland and France ${ }^{16}$ and from the United Kingdom, ${ }^{17} 22{ }^{23}$ as summarised by García-González et al. ${ }^{20}$

Eight polymorphisms have been identified in TGFB1: three in the upstream region of the gene at positions $-988,-800$, and -509 from the transcription start site; one in the nontranslated region at position +72 ; two non-synonymous coding SNPs in the signal peptide sequence: TGFBI T869C which changes codon $10\left(\right.$ Leu $^{10} \rightarrow$ Pro), and TGFB1 G915C which changes codon 25 ( $\mathrm{Arg}^{25} \rightarrow$ Pro); one SNP in the region of the gene coding for the precursor part of the protein is not present in the active form: TGFBI C1632T which changes codon $263\left(\mathrm{Thr}^{263} \rightarrow \mathrm{Ile}\right) ;$ and a one base pair deletion in intron 4 (713-8delC). ${ }^{16}{ }^{24}$ The TGFBI promoter polymorphisms and the T869C variant account for most of the diversity at this locus and a relatively small increase in diversity is

Table 2 TGFB 1 genotype and allele frequencies in patients with ankylosing spondylitis and controls

\begin{tabular}{|c|c|c|c|c|c|}
\hline \multirow[b]{2}{*}{ Genotype } & \multicolumn{2}{|c|}{ Controls $(n=194)$} & \multicolumn{2}{|c|}{ Patients ( $n=134$ ) } & \multirow[b]{2}{*}{ OR $(95 \% \mathrm{Cl})$} \\
\hline & n (\%) & AF & $\overline{n(\%)}$ & AF & \\
\hline \multicolumn{6}{|c|}{ TGFB1 T869C } \\
\hline$\pi$ & $80(41.2)$ & 65.5 & $57(42.5)$ & 64.6 & \multirow{3}{*}{$0.96(0.69$ to 1.33$)(p=0.81)$} \\
\hline TC & $94(48.5)$ & & $59(44.0)$ & & \\
\hline CC & $20(10.3)$ & 34.5 & $18(13.4)$ & 35.4 & \\
\hline \multicolumn{6}{|c|}{ TGFB1 G915C } \\
\hline GG & $168(86.6)$ & 93.3 & $107(79.9)$ & 89.6 & \multirow{3}{*}{$1.63(0.93$ to 2.84$)(p=0.09)$} \\
\hline GC & $26(13.4)$ & & 26 (19.4) & & \\
\hline CC & 0 & 6.7 & $1(0.7)$ & 10.4 & \\
\hline
\end{tabular}

$A F$, allele frequency; $\mathrm{Cl}$, confidence interval; OR, odds ratio. 
Table 3 Genotype, phenotype, and haplotype frequencies of the TGFB 1 polymorphisms in patients with ankylosing spondylitis and controls

\begin{tabular}{|c|c|c|c|c|c|c|c|}
\hline \multirow[b]{2}{*}{ TGFB1 haplotype } & \multicolumn{3}{|c|}{ Controls $(n=194)$} & \multicolumn{3}{|c|}{ Patients $(n=134)$} & \multirow[b]{2}{*}{$\mathrm{OR}^{*}(95 \% \mathrm{Cl})$} \\
\hline & $n(\%)$ & PF, n (\%) & HF (\%) & n (\%) & $\mathrm{PF}, \mathrm{n}(\%)$ & HF (\%) & \\
\hline 1.1 & $80(41.2)$ & $174(89.7)$ & 65.5 & $57(42.5)$ & $116(86.6)$ & 64.6 & \\
\hline 1.2 & $76(39.2)$ & & & $40(29.9)$ & & & 1.35 (0.69 to 2.66$)$ \\
\hline 1.3 & $18(9.3)$ & & & $19(14.2)$ & & & \\
\hline 2.2 & $12(6.2)$ & $96(49.5)$ & 27.8 & $10(7.5)$ & $57(42.5)$ & 25.0 & \\
\hline 2.3 & $8(4.1)$ & & & $7(5.2)$ & & & 1.32 (0.85 to 2.06$)$ \\
\hline 3.3 & 0 & $26(13.4)$ & 6.7 & $1(0.7)$ & $27(20.1)$ & 10.4 & 0.61 (0.34 to 1.11$)$ \\
\hline
\end{tabular}

*Overall odds ratios for carriership of haplotypes 1-3.

Haplotype 1: TGFB 1+869T-TGFB1+915G; haplotype 2: TGFB 1+869C-TGFB 1+915G; haplotype 3: TGFB 1+869C-TGFB 1+915C.

$\mathrm{Cl}$, confidence interval; $\mathrm{HF}$, haplotype frequency; $\mathrm{n}$, number of individuals; $\mathrm{OR}$, odds ratio; $\mathrm{PF}$, phenotype frequency.

attributable to the rare variants TGFBI C1632T and TGFBI G915C..$^{25}$

The TGFB1 polymorphism 713-8delC is more frequent in patients with osteoporosis than in normal controls and seems to be associated with very low bone mass in osteoporotic women and with low bone mass and increased bone turnover in both osteoporotic and healthy women. ${ }^{24}$ As bone mineral density is often decreased in AS patients, TGFBI polymorphisms seem to be of even more interest in this disease.

In a Japanese study, the frequency of the allele TGFBI 869T was found to be significantly higher in subjects with osteoporosis than in healthy individuals. ${ }^{26}$ On the other hand, the TGFB1 869C allele was associated with an increase in osteoporosis in white Australian women. ${ }^{27}$ The TGFB1 869C allele has also been associated with ossification of the posterior longitudinal ligament in the cervical spine and with spinal osteophytosis in Japanese patients. ${ }^{28} 29$ The development of spinal osteophytes is also a characteristic feature of AS.

The TGFB1 $915 \mathrm{G}$ allele is strongly associated with fibrotic lung disease. ${ }^{17}$ Apical pulmonary fibrosis is rare but well recognised in patients with AS. ${ }^{13}$ No association between Crohn's disease or ulcerative colitis, which are clinically related to AS, and TGFBI SNPs had been found in previous studies..$^{20} 30$

The genotype TGFB1 $915 \mathrm{GG}$ has been related to higher serum concentrations of TGF $\beta 1$ in a previous study. ${ }^{17} \mathrm{~A}$ combined study from Finland and the United Kingdom found a weak association between age of symptom onset of AS and the TGFB1 G915C SNP. ${ }^{25}$ Furthermore, this study noted a weak positive association of the rare allele TGFBl $1632 \mathrm{~T}$ with AS and also with a younger age at symptom onset of AS. These investigators concluded from their study that "the polymorphisms (G-800A, C-509T, T+869C, G+915C and $\mathrm{C}+1632 \mathrm{~T}$ ) in the TGFB1 gene play at most a small role in AS and that other genes on chromosome 19 are involved in the susceptibility to $\mathrm{AS}^{\prime \prime} .^{25}$

The results from our study do not show an association between the TGFB1 G915C SNP and AS, although the frequency of allele TGFB1 915G was greater in AS patients than in controls, but this difference did not reach significance $(p=0.09)$. In our group of AS patients no association between the TGFBI G915C SNP and a younger age of symptom onset of AS could be found.

As TGF $\beta$ may play a crucial role in the pathogenesis of AS, especially in new bone formation, further research is necessary to elucidate the role of TGF $\beta 1$ in this disease, and possibly open the way towards new pharmacological approaches for preventing the most disabling phenomenon of this disorder, ankylosis.

\section{Authors' affiliations}

$M$ van der Paardt, The Jan van Breemen Institute, VU University Medical Centre, Amsterdam, Netherlands
J B A Crusius, M A García-González, Laboratory of Immunogenetics, VU University Medical Centre

A S Peña, Department of Gastroenterology, VU University Medical Centre

B A C Dijkmans, I E van der Horst-Bruinsma, Department of

Rheumatology, VU University Medical Centre

\section{REFERENCES}

1 Gratacos J, Collado A, Pons F, Osaba M, Sanmarti R, Roque M, et al. Significant loss of bone mass in patients with early, active ankylosing spondylitis: a follow up study. Arthritis Rheum 1999;42:2319-24.

2 Mitra D, Elvins DM, Speden DJ, Collins AJ. The prevalence of vertebral fractures in mild ankylosing spondylitis and their relationship to bone mineral density. Rheumatology (Oxford) 2000;39:85-9.

3 Brown MA, Kennedy LG, MacGregor AJ, Darke C, Duncan E, Shatford IL, et al. Susceptibility to ankylosing spondylitis in twins: the role of genes, HLA, and the environment. Arthritis Rheum 1997;40:1823-8.

4 van der Linden SM, Valkenburg HA, de Jongh BM, Cats A. The risk of developing ankylosing spondylitis in HLA-B27 positive individuals. A comparison of relatives of spondylitis patients with the general population. Arthritis Rheum 1984;27:241-9.

5 Laval SH, Timms A, Edwards S, Bradbury L, Brophy S, Milicic A, et al. Wholegenome screening in ankylosing spondylitis: evidence of non-MHC geneticsusceptibility loci. Am J Hum Genet 2001;68:918-26.

6 Massague J. The transforming growth factor-beta family. Annu Rev Cell Biol 1990;6:597-641.

7 Blobe GC, Schiemann WP, Lodish HF. Role of transforming growth factor beta in human disease. N Engl J Med 2000;342:1350-8.

8 Centrella M, Horowitz MC, Wozney JM, McCarthy TL. Transforming growth factor-beta gene family members and bone. Endocr Rev 1994; 15:27-39.

9 Archer JR, Keat AC. Ankylosing spondylitis: time to focus on ankylosis. $J$ Rheumatol 1999;26:761-4.

10 Defrance T, Vanbervliet B, Briere F, Durand I, Rousset F, Banchereau J. Interleukin 10 and transforming growth factor beta cooperate to induce antiCD40-activated naive human B cells to secrete immunoglobulin Am J Exp Med 1992; 175:671-82.

11 van Vlasselaer $\mathbf{P}$, Punnonen J, de Vries JE. Transforming growth factor-beta directs IgA switching in human B cells. J Immunol 1992;148:2062-7.

12 Archer JR. Ankylosing spondylitis, IgA, and transforming growth factors. Ann Rheum Dis 1995;54:544-6.

13 Strobel ES, Fritschka E. Case report and review of the literature. Fatal pulmonary complication in ankylosing spondylitis. Clin Rheumatol 1997; 16:617-22.

14 Brewerton DA, Gibson DG, Goddard DH, Jones TJ, Moore RB, Pease CT, et al. The myocardium in ankylosing spondylitis. A clinical, echocardiographic, and histopathological study. Lancet, 1987;i, 995-8.

15 LeBlanc CM, Inman RD, Dent P, Smith C, Babyn P, Laxer RM. Retroperitoneal fibrosis: an extraarticular manifestation of ankylosing spondylitis. Arthritis Rheum 2002;47:210-14.

16 Cambien F, Ricard S, Troesch A, Mallet C, Generenaz L, Evans A, et al. Polymorphisms of the transforming growth factor-beta 1 gene in relation to myocardial infarction and blood pressure. The Etude Cas-Temoin de I'Infarctus du Myocarde (ECTIM) Study. Hypertension 1996;28:881-7.

17 Awad MR, El-Gamel A, Hasleton P, Turner DM, Sinnott PJ, Hutchinson IV. Genotypic variation in the transforming growth factor-betal gene: association with transforming growth factor-betal production, fibrotic lung disease, and graft fibrosis after lung transplantation. Transplantation 1998;66:1014-20.

18 Yamada Y, Miyauchi A, Goto J, Takagi Y, Okuizumi H, Kanematsu M, et al. Association of a polymorphism of the transforming growth factor-betal gene with genetic susceptibility to osteoporosis in postmenopausal Japanese women. J Bone Miner Res 1998;13:1569-76.

19 van der Linden S, Valkenburg HA, Cats A. Evaluation of diagnostic criteria for ankylosing spondylitis. A proposal for modification of the New York criteria. Arthritis Rheum 1984;27:361-8. 
20 García-Gonzalez MA, Crusius JB, Strunk MH, Bouma G, Perez-Centeno CM, Pals $G$, et al. TGFB 1 gene polymorphisms and inflammatory bowel disease. Immunogenetics 2000;51:869-72.

21 Schrijver HM, Crusius JB, Garcia Gonzalez MA, Polman CH, Pena AS, Barkhof $F$, et al. Gender-related association between the TGFB 1+869 polymorphism and multiple sclerosis. J Interferon Cytokine Res 2004;24:536-42.

22 Syrris P, Carter ND, Metcalfe JC, Kemp PR, Grainger DJ, Kaski JC, et al. Transforming growth factor-betal gene polymorphisms and coronary artery disease. Clin Sci (Lond) 1998;95:659-67.

23 Lympany PA, Avila JJ, Mullighan C, Marshall S, Welsh KI, du Bois RM. Rapid genotyping of transforming growth factor betal gene polymorphisms in a UK Caucasoid control population using the polymerase chain reaction and sequence-specific primers. Tissue Antigens 1998;52:573-8.

24 Langdahl BL, Knudsen JY, Jensen HK, Gregersen N, Eriksen EF. A sequence variation: 713-8delC in the transforming growth factor-beta 1 gene has higher prevalence in osteoporotic women than in normal women and is associated with very low bone mass in osteoporotic women and increased bone turnover in both osteoporotic and normal women. Bone 1997;20:289-94.
25 Jaakkola E, Crane AM, Laiho K, Herzberg I, Sims AM, Bradbury L, et al. The effect of transforming growth factor betal gene polymorphisms in ankylosing spondylitis. Rheumatology (Oxford) 2004;43:32-8.

26 Yamada Y, Hosoi T, Makimoto F, Tanaka H, Seino Y, Ikeda K. Transforming growth factor beta-1 gene polymorphism and bone mineral density in Japanese adolescents. Am J Med 1999; 106:477-9.

27 Dick IM, Devine A, Li S, Dhaliwal SS, Prince RL. The T869C TGF beta polymorphism is associated with fracture, bone mineral density, and calcaneal quantitative ultrasound in elderly women. Bone 2003;33:335-41.

28 Kamiya M, Harada A, Mizuno M, Iwata H, Yamada Y. Association between a polymorphism of the transforming growth factor-betal gene and genetic susceptibility to ossification of the posterior longitudinal ligament in Japanese patients. Spine. 2001;26: 1264-6; discussion, 1266-7).

29 Yamada Y, Okuizumi H, Miyauchi A, Takagi Y, lkeda K, Harada A. Association of transforming growth factor betal genotype with spinal osteophytosis in Japanese women. Arthritis Rheum 2000;43:452-60.

30 Schulte CM, Goebell H, Roher HD, Schulte KM. C-509T polymorphism in the TGFB1 gene promoter: impact on Crohn's disease susceptibility and clinical course? Immunogenetics 2001;53:178-82. 